\title{
Estimating Costs With Curvilinear Analyses For Learning
}

Dennis F. Togo, (E-mail: togo@unm.edu), University of New Mexico

\begin{abstract}
Even when the underlying mathematical relationship for the learning curve is a power function, most popular accounting textbooks perform a logarithmic transformation of the learning curve into a linear relationship. This transformation allows students to perform linear regression techniques; however, accounting students may be left with the misconception that all costs are linear. With the enhanced capabilities of spreadsheets, accounting students can now easily perform curvilinear analysis on historical learning data and then forecast costs where learning is present. The Smart Missile Company exercise illustrates this spreadsheet approach to teaching learning curves.
\end{abstract}

\section{INTRODUCTION}

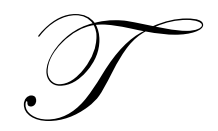

he learning curve is important for cost estimation, yet, most managerial and cost accounting textbooks (Hilton et al., 2000; Louderback et al., 2000) do not perform an analysis of historical data in determining an appropriate learning model and rate to predict labor hours. Instead, most textbooks (Blocher et al., 1999; Horngren et al., 2000) introduce the log-linear learning curve model with its cumulative average-time and individual unit-time variations and then simply predict labor hours for specified learning rates. Furthermore, a logarithmic transformation of the underlying mathematical power function into a linear function is commonly performed when analysis or forecasting of learning is discussed. Such an approach to learning curves may leave students with the misconception that all cost estimations are inherently linear, even when more direct and appealing curvilinear data analysis techniques are readily available with spreadsheets.

The Smart Missile Company exercise illustrates curvilinear data analysis in estimating labor hours when learning is present. The students statistically support their use of either the cumulative average-time or individual unit-time learning model based on historical data, estimate the model's learning rate and predict labor hours for cost estimation. The students enhance their data analysis skills beyond linear regression, and recognize that non-linear cost behavior can be easily analyzed. This exercise is designed for undergraduate and graduate business students in managerial or cost accounting courses.

\section{LEARNING CURVE OVERVIEW}

The learning curve relationship is commonly modeled with a mathematical power function described as a log-linear or constant percentage model. The log-linear model below recognizes that labor hours decrease systematically by a constant percentage each time the volume of production increases geometrically (usually a doubling of units).

$\left(A\right.$, or $\left.I_{n}\right)=a X^{b}$

The choice of a dependent variable is determined by whether the cumulative average-time learning model $(A)$ or the individual unit-time learning model $\left(I_{n}\right)$ is selected (Belkaoui, 1986). Hence, the left side of the relationship is either: $A=$ the average cumulative labor hours for $X$ number of units, or $I_{n}=$ the number of labor hours required to produce the last $n$th unit. The independent variables are defined as follows: $a=$ the number of labor hours required to produce the first unit, $X=$ cumulative number of units produced, and $b=$ learning exponent, which is always negative. The negative learning exponent $b$ is $(\log \mathrm{r}) /(\log \mathrm{f})$, where $\mathrm{r}$ is the rate of learning represented by the constant 
percentage decrease in hours, and $\mathrm{f}$ is the factor increase in output (usually in terms of 2). Hence, an $80 \%$ learning rate with a doubling of units has a learning exponent $b$ equal to -0.3219 , which is $(\log .80) /(\log 2)$.

\section{LEARNING CURVE EXERCISE: SMART MISSILE COMPANY}

The students are to prepare a bid for the building of $15 \mathrm{XYZ}$ missiles by Smart Missile Company. The company had built the XYZ prototype for the government because of its experience building the earlier ABC missiles. When the XYZ missile manufacturing specifications were released to other approved contractors, the government also released details of the $\$ 1,600,000$ cost in building the prototype. Costs for direct materials, direct labor, and variable manufacturing overhead are listed below. Other manufacturing overhead costs were $10 \%$ of total variable manufacturing costs. The $\$ 170,000$ equipment purchased by the government will be made available to the selected contractor.

Direct materials

Direct labor $(4,000$ hours @ \$100)

Variable manufacturing overhead (4,000 hours @ \$25)

Other manufacturing overhead $(\$ 1,300,000 @ 10 \%)$

Purchase of reusable government equipment

Total
$\$ 800,000$

400,000

100,000

130,000

170,000

$\$ 1,600,000$

The Smart Missile Company will not assume 4,000 direct labor hours incurred by the prototype for each of the next fifteen XYZ missiles because of learning, which was noticeably present when building the ABC missiles. With no significant turnover in its highly skilled labor force, the company anticipates that the next fifteen XYZ missiles can be built with the same amount of learning found for the sixteen earlier $\mathrm{ABC}$ missiles. The direct labor hours for each of the sixteen $\mathrm{ABC}$ missiles follow:

$\begin{array}{llllllll}\text { 1. } & 3,900 & 2 . & 2,740 & 3 . & 2,660 & 4 . & 1,980 \\ 5 . & 2,320 & 6 . & 2,000 & 7 . & 1,900 & 8 . & 1,700 \\ 9 . & 1,950 & 10 . & 1,950 & 11 . & 1,760 & 12 . & 1,540 \\ 13 . & 1,680 & 14 . & 1,320 & 15 . & 1,500 & 16 . & 1,100\end{array}$

\section{Curvilinear Data Analysis}

There are two related analyses of the $\mathrm{ABC}$ labor hour data: what learning curve model to adopt, and its percentage of learning. Using EXCEL, the students will generate a scatterplot of the direct labor hours incurred for the sixteen $\mathrm{ABC}$ missiles, and add to it a power function curve with its equation and $\mathrm{r}$-squared value. This is performed for the individual unit-time and the cumulative average-time models. They then determine which model is best, and calculate its learning rate. In the next section, the impact of learning will be estimated for the next $15 \mathrm{XYZ}$ missiles using the best model.

The data analysis begins with the students entering on a spreadsheet (see Exhibit 1) the data for the ABC missiles into two columns labeled as Unit and Individual. They then add columns for Total and Average. For the individual unit-time method, the students highlight the two columns Unit and Individual and use Chart Wizard to select XY (Scatter) as the chart type to generate the graph in Exhibit 1. The students right click on a data point within the graph, and then select Add Trendline and Power as the trend type from the drop down menus. Staying within Add Trendline, they select the Options tab and check Display equation on chart and Display R-squared value on chart.

Exhibit 1 displays the results for the individual unit-time model. The estimated learning curve is $\mathrm{Y}=3,798$ $\mathrm{X}^{-0.3582}$ and its $\mathrm{r}$-squared value is 0.8722 . For the cumulative average-time model, the students repeat the above steps except substitute Individual with Average. The estimated learning curve is $\mathrm{Y}=3,944 \mathrm{X}^{-0.2367}$ and its $\mathrm{r}$-squared value is 0.9968 . The data analysis supports the use of the cumulative average-time model because of its larger r-squared value. The EXCEL formula for computing the learning rate for the cumulative average-time model is $10^{\wedge}(-$ $0.2367 * \log (2))$ or rounded to $85 \%$. 
Exhibit 1: ABC Missiles Learning Curve Data and Analysis

\begin{tabular}{rrrrrrrr} 
Unit & Individual & Total & Average & Unit & Individual & Total & Average \\
\hline 1 & 3,900 & 3,900 & 3,900 & 9 & 1,950 & 21,150 & 2,350 \\
2 & 2,740 & 6,640 & 3,320 & 10 & 1,950 & 23,100 & 2,310 \\
3 & 2,660 & 9,300 & 3,100 & 11 & 1,760 & 24,860 & 2,260 \\
4 & 1,980 & 11,280 & 2,820 & 12 & 1,540 & 26,400 & 2,200 \\
5 & 2,320 & 13,600 & 2,720 & 13 & 1,680 & 28,080 & 2,160 \\
6 & 2,000 & 15,600 & 2,600 & 14 & 1,320 & 29,400 & 2,100 \\
7 & 1,900 & 17,500 & 2,500 & 15 & 1,500 & 30,900 & 2,060 \\
8 & 1,700 & 19,200 & 2,400 & 16 & 1,100 & 32,000 & 2,000 \\
\hline
\end{tabular}

Individual Unit-Time Model

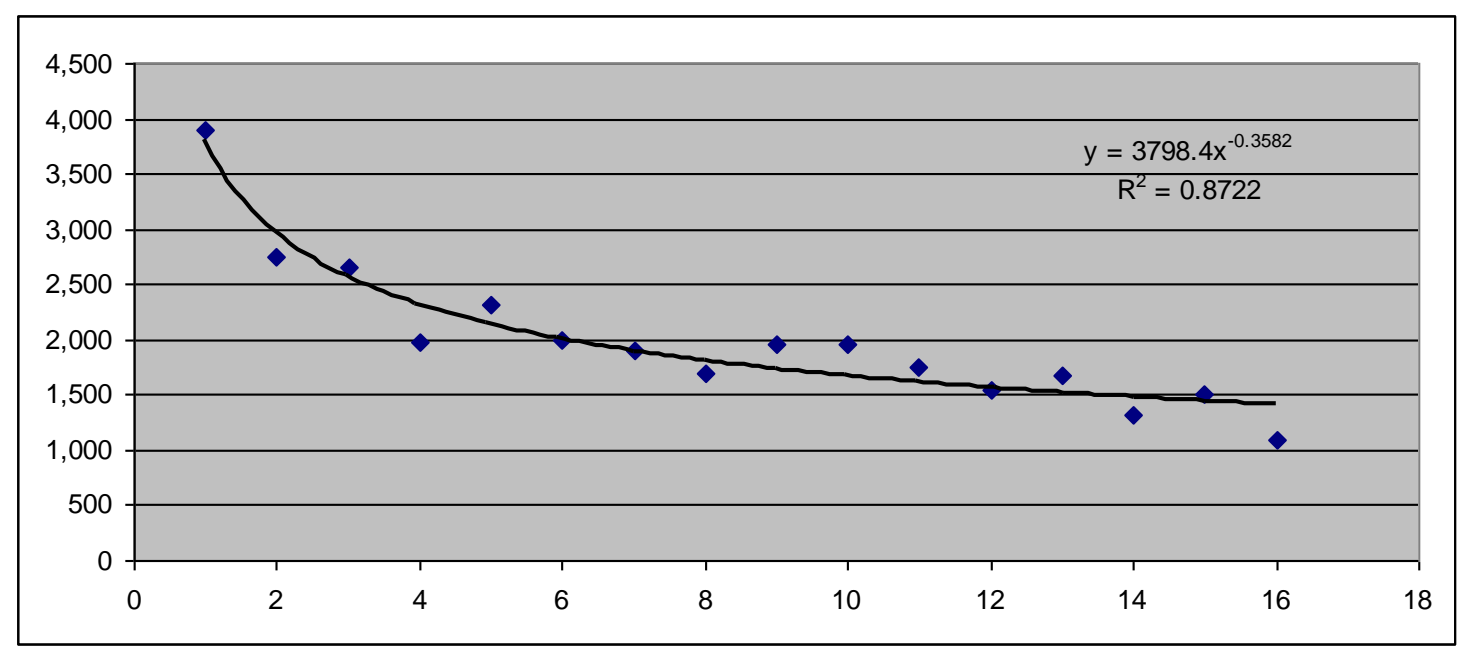

Cumulative Average-Time Model

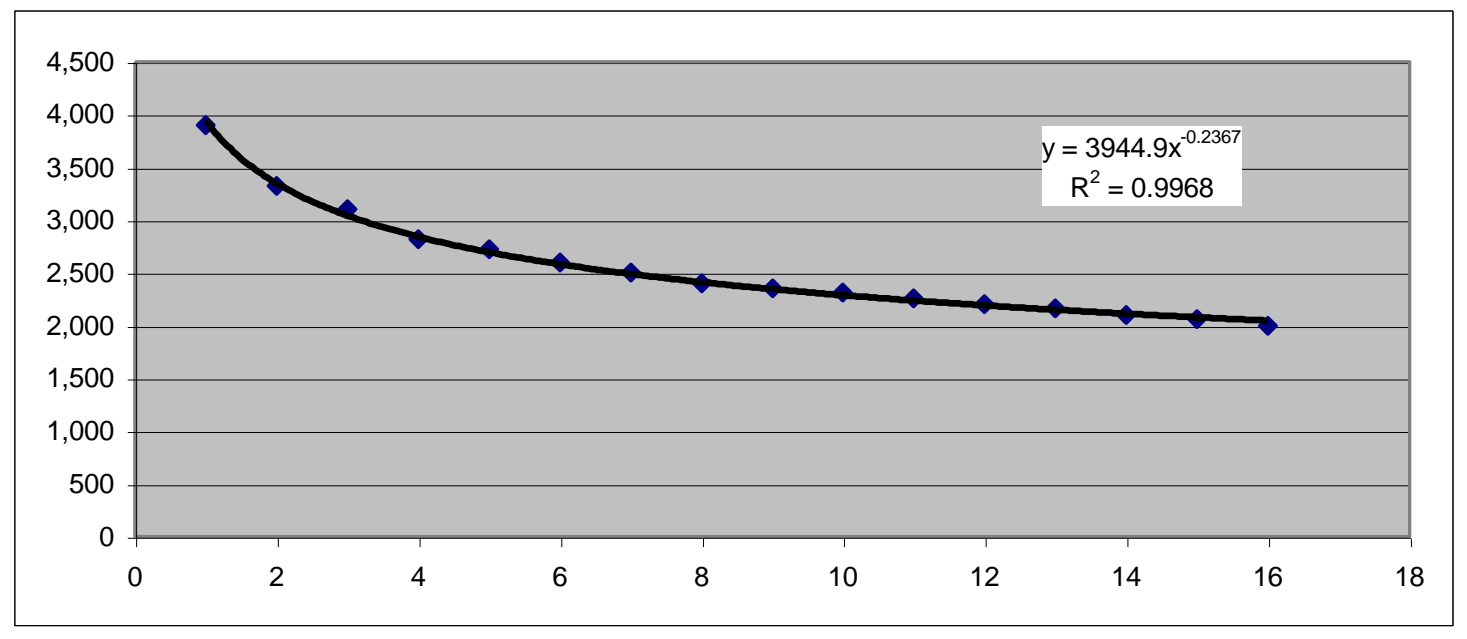




\section{Cost Estimation With Learning}

The students estimate the cost for the next $15 \mathrm{XYZ}$ missiles with the cumulative average-time model and its learning rate of $85 \%$. The formula $\operatorname{ROUND}\left(4000^{*} 16^{\wedge}(\log (0.85) / \log (2)), 0\right)$ computes the 2,088 average direct labor hours to complete the $16 \mathrm{XYZ}$ units, given 4,000 hours for the prototype. The total number of hours estimated to complete 16 units is $33,408(2,088 * 16)$, therefore, the number of hours to complete the $15 \mathrm{XYZ}$ missiles beyond the prototype is $29,408(33,408-4,000)$.

The $\$ 17,243,600$ bid is calculated for the next fifteen XYZ missiles based on 29,408 labor hours.

Direct materials $(\$ 800,000 * 15)$

Direct labor $(29,408$ hours @ \$100)

Variable manufacturing overhead $(29,408$ hours @ \$25)

Other manufacturing overhead (\$15,676,000@ @ 10\%)

Total $\begin{array}{r}\$ 12,000,000 \\ 2,940,800 \\ 735,200 \\ 1,567,600 \\ \hline \$ 17,243,600 \\ \hline\end{array}$

\section{Supplementary Tasks}

1. Solve for the logarithm of the cumulative average-time model. The solution is shown below. If $\mathrm{A}=3,944 \mathrm{X}$ ${ }_{-0.2367}, \log (\mathrm{A})=\log (3,944)+\log \left(\mathrm{X}^{-0.2367}\right)=3.5959-0.2367 * \log (\mathrm{X})$

2. Perform linear regression on ABC's equivalent logarithmic data. The result is the same as part 1. Proof: Assume $X=16$, then $\log (A)=3.5959-0.2367 * \log (16)=3.5959-0.2367 * 1.2041 \simeq 3.3088$. The antilog for $\log (\mathrm{A})=3.3088$ is $\mathrm{A}=10^{+3.3088}=2,088$.

3. Have the students contrast assumptions for the cumulative average-time model with the individual unit-time model. With the same $85 \%$ learning rate, the individual unit-time model estimates $37,534(41,534-4,000)$ labor hours for the next 15 missiles beyond the prototype.

$\begin{array}{llllllll}\text { 1. } & 4,000 & 2 . & 3,400 & 3 . & 3,092 & 4 . & 2,890 \\ 5 . & 2,743 & 6 . & 2,628 & 7 . & 2,535 & 8 . & 2,457 \\ 9 . & 2,390 & 10 . & 2,331 & 11 . & 2,280 & 12 . & 2,234 \\ 13 . & 2,192 & 14 . & 2,154 & 15 . & 2,120 & 16 . & 2,088\end{array}$

Exercise Effectiveness

The students enjoy this exercise based on course evaluations and in-class discussions. The spreadsheet modeling of learning curves broadens and enriches their study of cost estimation. Students recognize that any managerial decision where learning takes place can benefit from curvilinear data analysis of available historical data. Furthermore, they become aware of other nonlinear relationships such as polynomial, exponential, and moving average that can also be analyzed and modeled using the same approach.

\section{OTHER FACILITATIVE USES OF COMPUTERS}

As spreadsheets become more powerful and user-friendly, accounting educators can rejuvenate their teaching approaches for traditional accounting topics. For example, the teaching of topics such as master budgets (Togo, 1991), reciprocal service-department cost allocations (Savage and Wilburn, 1997) and capital budgeting (Togo and McNamee, 1996) are facilitated by spreadsheets. In addition, risk analysis with Monte Carlo simulation is conducive to accounting topics such as pensions (Kelliher et al., 1997), flexible budgeting (Nordhauser and Chau, 1997), and capital budgeting and projecting cash flows or operating income (Togo, 2004). 


\section{REFERENCES}

1. Belkaoui, A. (1986) The Learning Curve: a management accounting tool. Westport, CT: Greenwood Press.

2. $\quad$ Blocher, E.J., Chen, K.H., and Lin, T.W. (1999) Cost management: A strategic emphasis. New Jersey: Prentice Hall.

3. Hilton, R.W., Maher, M.W., and Selto, F.H. (2000) Cost management: Strategies for business decisions. Boston: McGraw Hill.

4. Horngren, C.T., Foster, G., and Data, S.M. (2000) Cost accounting: A managerial emphasis. New Jersey: Prentice Hall.

5. Kelliher, C., Fogarty, T., and Goldwater, P. (1996) Introducing uncertainty in the teaching of pensions: A simulation approach. Journal of Accounting Education 14 (1) Spring, 69-98.

6. Louderback, J.G., Holmen, J.S., and Dominiak, G.F. (2000) Managerial accounting. Cincinnati, Ohio: Southwestern.

7. Nordhauser, F. and Chau, C-T. (1997) Beyond flexible budgeting: Performing stochastic simulation with a spreadsheet add-in. Accounting Educators' Journal IX (1) Spring, 101-114.

8. Savage, K. and Wilburn, N.L. (1997) Teaching the reciprocal method of service-department cost allocations using a spreadsheet approach. Accounting Educators' Journal IX (2) Fall, 142-155.

9. Togo, D.F. (1991) Acquiring an overview of accounting as an information system for planning, control, and reporting: A spreadsheet approach. The Journal of Information Systems 5 (2) Fall, 73-77.

10. Togo, D.F. (2004) Risk analysis for accounting models: A spreadsheet simulation approach. Journal of Accounting Education 22 (2) Spring, 153-163.

11. Togo, D.F. and McNamee, A.H. (1996) Teaching spreadsheet risk analysis for capital budgeting. Accounting Educators' Journal VIII (1) Spring, 172-179.

\section{NOTES}


NOTES 